\title{
Emotional Strategies for Vocabulary Learning
}

\author{
Ramla Ghali, Claude Frasson \\ Département d'informatique et de recherche opérationnelle \\ Université de Montréal \\ Canada \\ \{ghaliram, frasson\}@iro.umontreal.ca
}

\begin{abstract}
Emotions have a crucial role in our social life in general and in our professional life and education in particular. Besides, they proved essential in information processing systems, more specifically in Intelligent Tutoring Systems (ITS). In this article, we present new strategies integrated into an ITS' tutor module and intended to teach children the vocabulary of a foreign language, namely English. These strategies can generate emotions for students making words memorization easier. We describe the experimentation carried out to validate these emotional strategies as well as the results obtained.
\end{abstract}

Keywords. Emotional strategy, emotion elicitation, knowledege memorization.

\section{INTRODUCTION}

Language learning is a multi-level task that integrates elements such as words, syntax, pronunciation and culture [1]. It seems then that learning a language other than mother tongue is not a simple task, but rather requires that the learner make a lot of effort to assimilate all these elements at the same time. Providing some help in this situation would facilitate both the task of learning and an efficient acquisition of the language. For these reasons, several researchers with different backgrounds (language teaching, computer science, linguistics) have focused on the study and design of successful learning environments for language learning. To design these tools, certain authors [2, 3] have adopted multimedia resources such as texts, images, sounds, videos, etc. They found that these techniques are effective in vocabulary learning among students.

However, recent studies in neuroscience have shown that emotions are widely related to diverse cognitive processes, such as attention, memory, perception and decision-making $[4,5]$. This leads us to conclude that emotions could influence the learning process itself. It will then be useful to take them into consideration in any learning activity, particularly in memorization tasks. Moreover, in the language learning context, several researchers [6, 7] have shown that information including an emotional component is more easily memorized than information presented without an emotional tone or with emotion deemed "neutral".

In this paper, we present four different strategies aiming to teach English vocabulary to children. The first strategy called reference-strategy consists in presenting the lesson without any action on the emotional state of the student, in other words we present an English course to the student without any pedagogical intervention from a human or an automatic tutor. The three other strategies use a virtual tutor that is responsible to both present the course to the student and induce emotions using a hybrid technique based on music and tone of voice.

The first section of this paper provides a related literature and works realized on different methods for teaching foreign languages as well as different tools able to induce emotions in ITS, more specifically the acoustic parameters of voice and emotional induction techniques. The second section describes the experiment set up to validate our emotional strategies. We show and discuss results obtained from this experiment. Finally, we present some possible extension of these works.

\section{PREVIOUS WORKS}

Every foreign language is based on a very rich knowledge base made up of a set of words containing the vocabulary and a set of rules linked to the grammar. Learning these two elements at the same time is complex and requires a lot of effort from the student. The use of Intelligent Tutoring Systems (ITS) could dramatically help this type of learning. However, works in this area are rare and mainly confined to the use of multimedia resources. For example, Groot [8] has developed a system called CAVOCA to teach English vocabulary to German students; it teaches words pronunciation and distinguishes the meaning of words according to the context. Kim and Gilman [3] tried to evaluate the respective or combined influence of lexical terms on learning, in a self-instructive hypermedia environment, in the form of texts, images and sound. They showed that simultaneous presentation of media (text, graphic illustration with or without sound) promotes learning vocabulary. Recently, Baturay and his colleagues [2] have developed a hypermedia system called WEBVOCLE to facilitate vocabulary learning; they combined audio-visual media with a memorization technique called spaced repetition which was efficient.

Given that emotions play a crucial role in cognitive processes and especially in memorization tasks, it will be useful to consider them in this application. Moreover, as already mentioned, several works $[9,10]$ have shown that the affective dimension of information focalizes subject attention 
and can also enable personal memories that give rise to more reliable recalled events. Thus, information with emotional overtones could be more easily retained than neutral information.

Taking emotion into consideration in an ITS consists essentially in the management and the regulation of student's emotions during a learning session. To manage the emotions of the student, computer scientists use several methods, including the use of a virtual tutor that communicates with the student through voice. This tutor usually expresses emotions by respecting a set of vocal characteristics. These characteristics, called acoustical parameters of voice are defined from studies on encoding emotions. For example, Scherer and Oshinsky [11] have identified seven two-level factors (amplitude variation, pitch variation, intonation contour, pitch level, tempo, envelope and filtering) that allow the expression of eight specific emotions (anger, boredom, fear, surprise, pleasure, happiness, sadness and disgust).

Other than the expression of emotions through voice, psychologists use various methods to generate particular emotions (called emotional induction techniques). These methods differ mainly in the way to induce a particular emotional state. Two categories, direct or indirect induction techniques, can be distinguished. In direct induction techniques the subject is informed in advance of the induction; for instance he has to read a text suggesting an emotional state (I am sad to-day). In indirect induction techniques the subject is not aware of the induction process and he is just submitted to a specific induction technique. Several techniques can be used: a musical induction procedure $[12,13]$ in which participants listen to musical excerpts that are likely to induce a particular emotional state (for example: joy, anger, fear, sadness, etc.), showing emotionally-charged films [14, 15], presentation of images [16], telling of stories [17], etc. Generally, these techniques can be used alone or combined such as showing videos excerpts associated with musical pieces [18] in order to maintain the state induced by these videos.

To generate emotions we used a hybrid technique which combines two mood induction techniques known in psychology and based on music and vocal intonation. Here, to elicit an emotion, we have mainly used the tone of the tutor voice. Moreover, to maintain the state induced by this voice, we have used a musical excerpts that are likely to induce the appropriate emotional state (joy, fear, or anger) corresponding to the vocal intonation.

Finally, to facilitate vocabulary learning, we used here an association technique in which each word is associated to an image.

In the next section, we describe in details the experiment carried out in order to estimate the impact of emotional strategies on a set of participants.

\section{EXPERIMENT}

The goal of this experiment is to submit students to emotional inductions and measure the impact of elicited emotions on their performance. The tutor will use four emotional strategies described. The data collected will subsequently decide on the effectiveness of these strategies.
In the following we detail the student sample selected as well as the experimental procedure.

\section{A. Subjects}

A total of 41 subjects (12 boys, 29 girls) from different Quebec schools participated in this study: the St-AntoineMarie-Claret, St-Isaac-Jogues, Notre-Dame-de-l'Assomption and Marcel-Vaillancourt schools. The subjects were 6-8 years old (mean age $=7.32, \mathrm{SD}=0.57$ ).

\section{B. Experimental procedure}

The experiment is web-based and is composed of four steps as illustrated by the following figure.

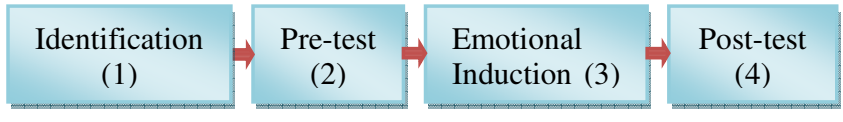

Figure 1. The experimental steps

Step1: In the first step the student is invited to identify himself by using a login and a password. The login is already established at a primarily phase and is used to transmit data on each student.

Step2: In the second step the student has to assess his knowledge. Thus, he is prompted to choose the word corresponding to each image from a list of radio buttons representing the different choices. The pre-test contains five words where each correct answer is worth two points and each wrong answer is worth 0 for a total of 10 points. At the end of the test, a knowledge level is assigned to each student: beginner (if the learner's obtained score is less or equal to 2 ), intermediate (between 4 and 6) and advanced (higher or equal to 8).

Step3: In the third step an English course is presented to the participant as shown in Fig. 2. The aim of this simple course is to learn eight different English words online.

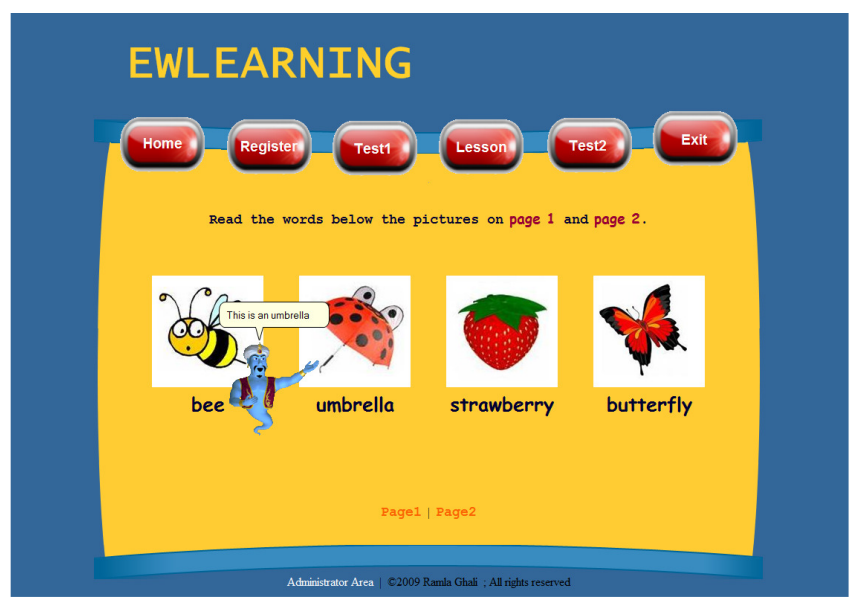

Figure 2. Example of interface showing the English course

The course is presented to all students with four different strategies randomly generated. The first strategy (reference-strategy) consists in exposing the lesson without intervention of the tutor and without inducing an emotional 
state (neutral emotional state). The second, third and fourth strategies consist in presenting the lesson with the tutor inducing respectively joy, fear and anger. The following table summarizes these four strategies.

TABLE I. DESCRIPTION OF THE EMOTIONAL STRATEGIES

\begin{tabular}{|ccccc}
\hline Strategy & Emotion & Tutor & $\begin{array}{l}\text { Emotional } \\
\text { Induction } \\
\text { Music }\end{array}$ & $\begin{array}{c}\text { Emotional } \\
\text { Induction } \\
\text { Voice Tone }\end{array}$ \\
\hline Strategy $\mathbf{1}$ & Neutral & No & No & No \\
Strategy 2 & Joy & Yes & $\begin{array}{c}\text { Delibes's Mazurka } \\
\text { from Coppelia [19] }\end{array}$ & Yes \\
Strategy 3 & Fear & Yes & $\begin{array}{c}\text { Ives's } \\
\text { Halloween [20] }\end{array}$ & Yes \\
Strategy $\mathbf{4}$ & Anger & Yes & $\begin{array}{l}\text { Moussorgsky's } \\
\text { Night on Bald } \\
\text { Mountain [21] }\end{array}$ & Yes \\
\hline
\end{tabular}

Step 4: In the last step the participant is invited to answer a post-test to assess the knowledge acquired after the course. This post-test is very similar to the pre-test described in step 2. It contains the same number of questions and the same task is required (see Fig. 3). Both tests are similar to check if there is an improvement in the learner's result after the course, as well as the level of improvement.

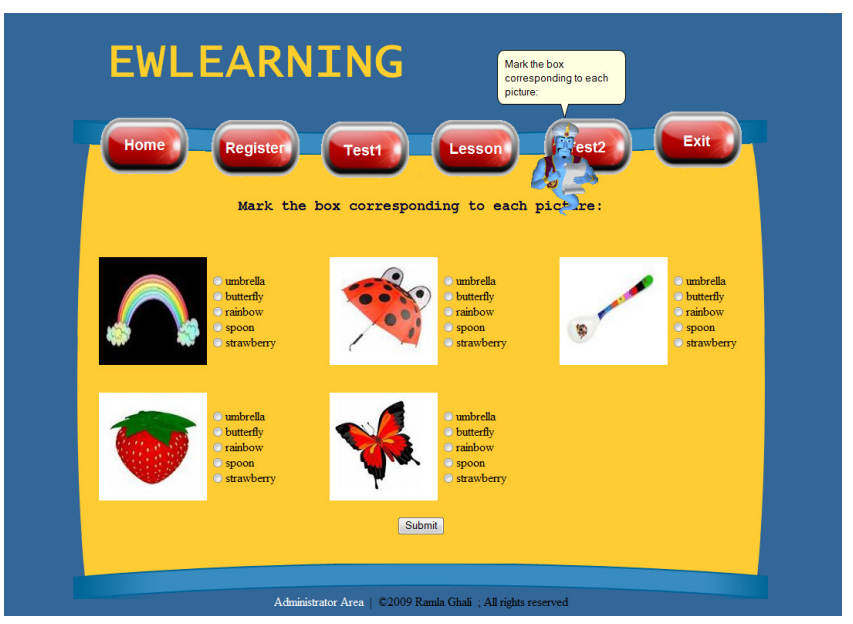

Figure 3. Interface representing the post-test

\section{RESULTS AND DISCUSSION}

The main goal of the experiment described above is to test the effectiveness of the four strategies. To do so, we distributed these strategies randomly among the participants using a specific algorithm able to equally assign all the strategies. Table 2 presents the obtained distribution of emotions among the participants.
TABLE II. EMOTIONS REPARTITION

\begin{tabular}{|c|c|c|c|}
\hline $\begin{array}{c}\text { Emotional } \\
\text { strategy }\end{array}$ & M & F & Total \\
\hline Neutral & 5 & 4 & 9 \\
\hline Joy & 1 & 10 & 11 \\
\hline Fear & 3 & 7 & 10 \\
\hline Anger & 3 & 8 & 11 \\
\hline Total & $\mathbf{2 1}$ & $\mathbf{2 9}$ & $\mathbf{4 1}$ \\
\hline
\end{tabular}

In order to test the effectiveness of the emotional strategies previously mentioned, we have compared the knowledge level distribution of the students before and after the course as shown in Fig. 4. We can also notice that $86 \%$ (15-2) of beginner students had improved their knowledge level and change it to "Intermediate" or "Advanced". Besides, we can see that after the course, the number of students having an "Advanced" knowledge level had increased considerably (from 4 to 22 ).

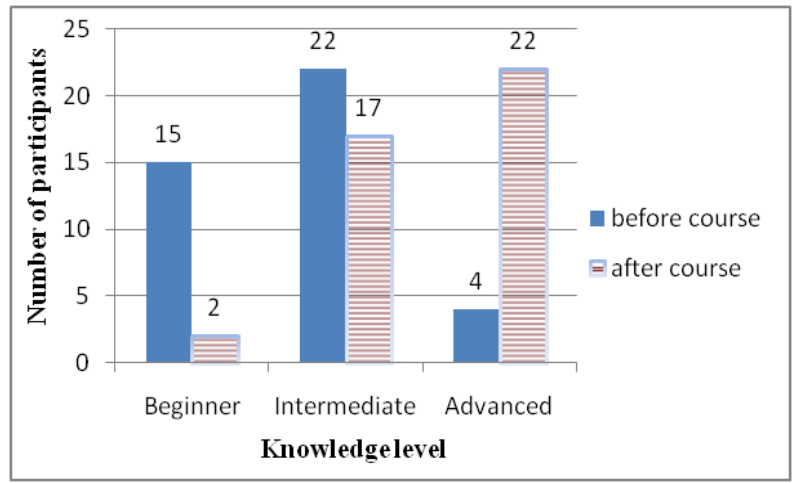

Figure 4. The knowledge level distribution before and after the course

Moreover, we have used a t-test (Student test) to compare the means of the score improvement of the two groups; a group which learned the course with an emotional strategy (joy, fear and anger), and a group taught without emotion inducing procedure (neutral strategy). The improvement score is calculated by subtracting the final score obtained in the post-test from the initial score obtained in the pre-test. Both groups of students were then the qualitative independent variables of the t-test; however the improvement score was the quantitative dependent variable used. The result of this t-test $(\mathrm{t}$-value $=2.25, \mathrm{df}=39, \mathrm{p}=.03 / 2<.05)$ proved that the group of students who have learned the course with a mood induction technique has a mean significantly higher than the one without emotion elicitation.

Another interesting result is presented in Fig. 5 where we have computed for each emotional strategy the average of students' grades obtained in the initial test (pre-test) and the grades obtained in the final test (post-test). Thus, we notice, for all the strategies, that the mean post-test score (score 2) is higher than the initial score (score 1). However if we look at Fig. 6 which shows the score improvement, we can see that the difference between the means is not the same for all these 
strategies. For instance, the mean improvement score obtained by all students taking the course without tutor and without mood induction technique is the least (mean of score improvement of 2.22). Nevertheless, the strategy of anger was ranked third (mean of score improvement of 3.45), the strategy of joy was ranked second and the strategy of fear is the first. So, we can say that implicitly induced emotions can affect student performance. Moreover, they enhanced words memorization.

Besides, we can notice that not only positive emotions can enhance vocabulary learning but also some negative emotions, such as fear and anger, can promote the learning process. Indeed, Fig. 6 already shows that the average score improvement of fear is the highest (4.6). This result could be explained by the effect of fear on student's performance which pushes him to avoid suffering from bad situations such as failure in this case.

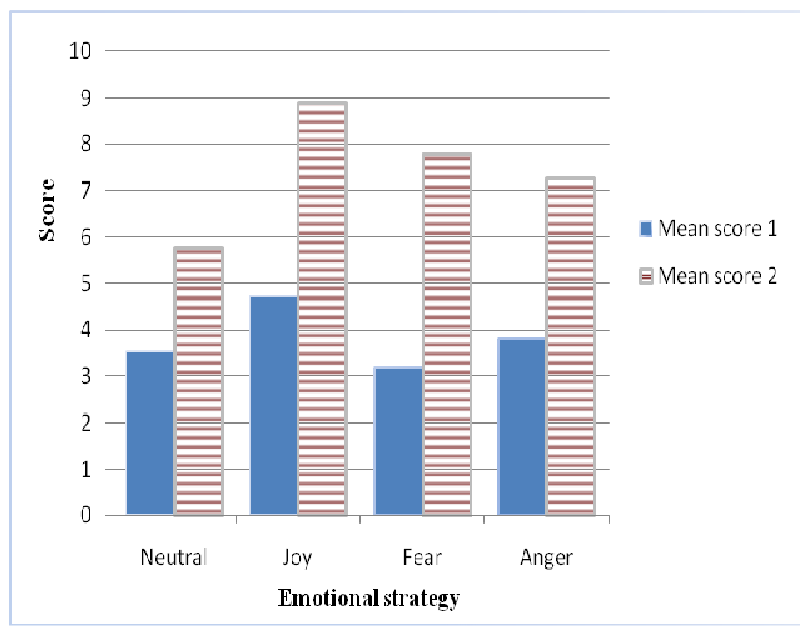

Figure 5. Mean of scores for each strategy

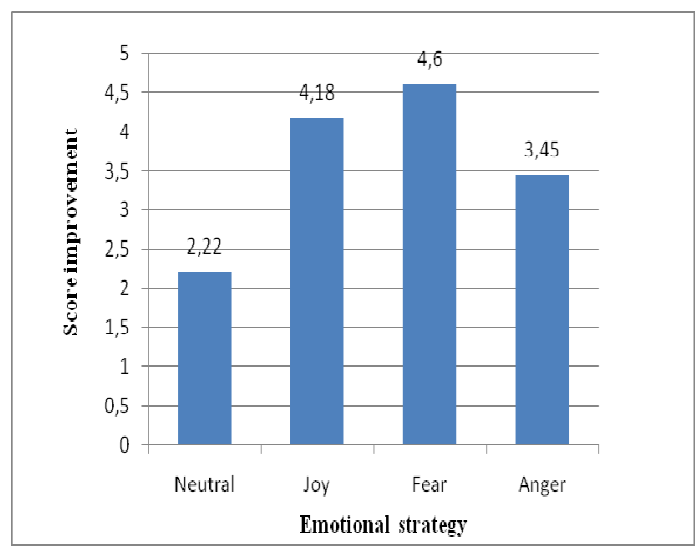

Figure 6. Average of score improvement for each strategy

\section{CONCLUSION AND FUTURE WORKS}

In this paper, we have presented a new way to improve the learning of vocabulary by using an emotional technique of mood induction, which combines music and tutor's tone of voice. Thus, we have used here three different emotional strategies aiming to induce respectively joy, fear and anger. Results have confirmed that the induced emotion has a significant influence on the performance. Furthermore, the mean improvement scores of students having learned the course with an emotional strategy (joy, fear or angry) is notably higher than that of students subject to a neutral one.

New works are under way in which we try to find the optimal emotional induction strategy according to the temperament of the participant (in the present experiment induced emotions were distributed randomly). For that purpose we considered temperament data as an additional component to obtain in step 1 (identification). Three temperament factors were considered ("Surgency", "Negative Affectivity" and "Effortful Control") in order to adequately induce the emotional strategies for the students. Data are obtained using the Children Behavior Questionnaire Very Short Form (CBQ-VSF) [22], a caregiver report measure of the three broad factors of temperament for children aged 3 to 8 years. The first results obtained show that we don't have to induce negative emotions for children with negative affectivity and children with surgency need to stand into more positive emotions.

We plan for future research to keep analyzing the experiment data in order to adapt these emotional strategies to the student's behavioral profile. We plan to develop an intelligent agent able to adapt the course according to the learner's temperament. The main purpose of such agent is to maximize the student's performance in learning English vocabulary. In addition, we intend to expand the knowledge base of our ITS' curriculum by increasing the number of vocabulary words to learn.

\section{ACKNOWLEDGMENT}

We address our thanks to the FQRSC (Fonds Québécois de la Recherche sur la Société et la Culture) and the NSERC (National Science and Engineering Research Council) for supporting this project.

\section{REFERENCES}

[1] M. Heilman, and M. Eskenazi, "Language Learning: Challenge for Intelligent Tutoring System," in ITS 06, Taiwan, 2006.

[2] M. Baturay, S. Yildirim, and A. Daloglu, "Effects of Web-Based Spaced Repetition on Vocabulary Retention of Foreign Language Learners," Eurasian Journal of Educational Research (EJER), vol. 8, no. 34, pp. 17-36, 2009.

[3] D. Kim, and D. A. Gilman, "Effects of text, audio, and graphic aids in multimedia instruction for vocabulary learning," Journal of educational technology \& society, vol. 11, no. 3, pp. 114-126, 2008.

[4] A. Damasio, Descartes' Error: Emotion, Reason, and the Human Brain. Haper Perennial, 1995.

[5] A. M. Isen, Positive Affect and Decision Making, Handbook of emotions, M. Lewis \& J. Haviland-Jones ed., pp. 417-435, New York: Guilford, 2000.

[6] S. Dutta, and R. N. Kanungo, Affect and memory: A reformulation, Oxford, England: Pergamon Press, 1975.

[7] P. Chalfoun, I. Lopes De Menezes, and C. Frasson, "Emotional Retention Agent For Foreign Language E-learning," AACE World Conference on E-learning in Corporate, Government, Healthcare, \& Higher Education. E-LEARN, 2007. 
[8] P. Groot, "Computer Assisted Second Language Vocabulary Acquisition," Language Learning \& Technology, vol. 4, no. 1, pp. 60$81,2000$.

[9] S. A. Charistianson, and E. F. Loftus, "Remembering emotional events: The fate of detail information," Cognition \& Emotion, vol. 5, pp. 81-108, 1991.

[10] A. Syssau, and D. Brouillet, "Rôle de la valeur affective et de la nature du texte dans la récupération du souvenir chez les personnes âgées," l'Année Psychologique, vol. 96, pp. 85-112, 1996.

[11] K. R. Scherer, and J. S. Oshinsky, "Cue utilization in emotion attributions from auditory stimuli," Motivation and Emotion, vol. 1, no. 4, pp. 331-346, 1977.

[12] D. M. Clark, "On the induction of depressed mood in the laboratory: Evaluation and comparison of the Velten and musical procedures," Advances in Behaviour Research \& Therapy, vol. 5, no. 1, pp. 27-49, 1983.

[13] P. M. Niedenthal, J. B. Halberstadt, and M. B. Setterlund, "Being happy and seeing "happy": Emotional state mediates visual word recognition," Cognition and Emotion, vol. 11, no. 4, pp. 403-432, 1997.

[14] R. S. Lazarus, J. C. Speisman, A. M. Mordkoff and L.A. Davidson, "A laboratory study of psychological stress produced by a motion picture film," Psychological Monographs, vol. 76, 1962.
[15] J. J. Gross, and R. W. Levenson, "Emotion elicitation using films," Cognition \& Emotion, vol. 9, no. 1, pp. 87-108, 1995.

[16] P. J. Lang, M. M. Bradley, and B. N. Cuthbert, "International Affective Picture System (IAPS)," Technical Manual and Affective Ratings, University Floride, 1995.

[17] A. Gerrards, K. Spies, and F. W. Hesse, "Experimental inductions of emotional states and their effectiveness : a review," British Journal of Psychology, vol. 85, pp. 55-78, 1994.

[18] P. M. Niedenthal, J. B. Halberstadt, and A. H. Innes-Ker, "Emotional response categorization," Psychological Review, vol. 106, no. 2, pp. 337-361, 1999.

[19] L. Delibes, R. Bonynge, and L. Minkus, "The 3 ballets," Enregistrement sonore, Decca, 1999.

[20] C. Ives, P. Zukofsky, and G. Kalish, "Chamber music," Enregistrement sonore, Columbia, 1971.

[21] L. Maazel, I. Markevitch, M. P. Mussorgsky, A. Borodine, M.I. Glinka, N. Rimsky-Korsakov, A.K. Lyadovand and P. Berliner, "Russie eternelle," Enregistrement sonore, Deutsche Grammophon, 1993.

[22] S. P. Putnam, and M. K. Rothbart, "Development of Short and Very Short Forms of the Children's Behavior Questionnaire," Journal of Personality Assessment, vol. 87, no. 1, pp. 102-112, 2006. 